\title{
INSERÇÃO DO MÉTODO DESDOBRAMENTO DA FUNÇÃO QUALIDADE (QFD) NO PLANEJAMENTO DO SERVIIÇO DE ENFERMAGEM 1
}

\author{
THE USE OF QUALITY FUNCTION DEPLOYMENT METHOD (QFD) IN THE \\ NURSING SERUICE PLANINING
}

\section{INSERCIÓN DEL MÉTODO DESDOBLAMIENTO DE LA FUNCIÓN CALIDAD ( CFD) EN EL. PLANEAMENTO DEL SERUICIO DE ENFERMERÍA}

\section{Laura Misue Matsuda ${ }^{2}$ Yolanda Dora Martinez Évora ${ }^{3}$ Flávio Souto Boan ${ }^{4}$}

RESUMO: Este trabalho objetivou propor uma alternativa que viabilize a qualidade do Serviço de Enfermagem através de um estudo exploratório-descritivo que contou com a participação de 114 clientes hospitalizados. Elaborou-se um modelo de planejamento seguindo as etapas e ações delineadas pelo método Desdobramento da Funçāo Qualidade que é alicerçada na abordagem da Gestão pela Qualidade Total. Foram estabelecidas dezessete etapas que buscou levantar as necessidades dos clientes e, através de desdobramentos e priorizações sucessivas, determinou-se as principais Características de Qualidade e Procedimentos que subsidiaram a padronização e monitoramento das ações propostas. Os resultados mostram que este método é viável também ao Planejamento da Qualidade do serviço de enfermagem, pois o mesmo possibilitou visualizar todo o contexto, fornecendo subsídios para a tomada de decisōes mais coerentes e consistentes.

UNITERMOS: Enfermagem - Qualidade - Desdobramento - Cliente.

ABSTRACT: This research aimed at suggesting an alternative to achieve quality in Nursing Service through an exploratory-descriptive study with 114 patients. A planning model was has been elaborated the steps and actions outlined by the Quality Function Deployment Method. It was based on Total Quality Control management approach. Seventeen steps has been established in order to seek clients' needs and through successive deployment and priority, the main Quality Features and Procedures which supported standardisation and monitoring of proposed actions has been determined. The outcomes showed that this method is feasible for Nursing Service Quality Planning because it has enabled to enview the context as a whole, providing major degree of certainty on decisions.

KEYWORDS: Nursing - Quality - Deployment - Client.

${ }^{1}$ Este artigo é parte de Dissertaçăo de Mestrado e contou com a subvençăo da CAPES.

2 Enfermeira - Doutoranda do Curso de Pós-Graduaçăo Area Enfermagem Fundamental da Escola de Enfermagem de Ribeirăo Preto - USP.

${ }^{3}$ Enfermeira Prof a. Dra. - Docente do Dept ${ }^{\circ}$. de Enfermagem Geral e Especializada da EERP - USP.

${ }^{4}$ Engenheiro Eletricista - Mestre em Engenharia da Produçăo na UFMG - MG. Consultor da Fundaçăo Christiano Ottoni - BH. 
RESUMEN: Este trabajo objetivo proponer una alternativa que viabilize la calidad del Servicio de Enfermería por medio de un estudio exploratorio-descriptivo que conto con la participación de 114 clientes hospitalizados. Fué elaborado un modelo de Planeamiento siguiendo las etapas y acciones delineadas por el método Desdoblamiento de la Función Calidad que es baseada en el abordagen de la Gestion por la Calidad Total. Fueron establecidas diecisiete etapas que buscaron levantar las necesidades de los clientes y através de desdoblamientos y prioritizaciones sucesivas fueron determinadas las principales Características de Calidad y Procedimientos que subsidiaron la padronización y monitoramiento de las acciones propuestas. Los resultados muestran que este método es viable tambien al Planeamiento de la Calidad del Servicio de Enfermeria, pues el mismo posibilitó visualizar todo el contexto, forneciendo subsidios para la tomada de decisiones más coherentes y consistentes.

UNITÉRMINOS: Enfermeria - Calidad - Desdoblamiento - Cliente.

\section{INTRODUÇÃo}

A enfermagem, que segundo a luz da etimologia significa "ato ou efeito de tratar os enfermos" (Angerami \& Correia, 1989:338), desde os seus primórdios, tem se desenvolvido de acordo com as mudanças sócio-político-econômicas vigentes no contexto da sua inserção. Dessa forma, a sua atuação tem sido caracterizada por períodos de avanços e retrocessos determinados pela história da civilização, suprindo ou tentando suprir as necessidades de saúde.

Percebemos, entretanto, que o setor da saúde, e com isso também a enfermagem, já não é capaz de acompanhar as mudanças do contexto da economia globalizada e o que se vê é um sistema desgastado alicerçado num modelo administrativo já ultrapassado que data do início deste século.

Hoje, devido à competição exacerbada do mercado, as organizações estão cada vez mais dependentes de conhecimentos e habilidades para obter a sua sobrevivência. Neste âmbito, a mudança de filosofia institucional e profissional voltada para a inovação, a parceria e a humanização passam a ser conceitos fundamentais.

Consideramos, então, que, por estar inserida no contexto acima, a enfermagem necessita repensar a sua prática de modo que assuma o seu papel social e as responsabilidades a ela inerentes. Para tanto, deverá buscar novas alternativas ainda que em outras áreas que propicie a sua inserção num ambiente de permanente mudança, utilizando-se de uma abordagem cujo foco central é o Homem.

O trabalho empírico, fragmentado, descontínuo, a existência de níveis hierárquicos rigidamente delimitados, trabalhadores atuando em condições de extrema insegurança e muitas vezes sem preparo, baixa remuneração e falta de reconhecimento sẩo algumas das características que se fazem presentes no cotidiano da enfermagem.

Entendemos que os fatores acima desestimulam a prática dessa profissão, entretanto, julgamos não serem suficientes a ponto de justificar o comodismo e a inércia de muitos profissionais. É preciso, sim, que atuemos ao mesmo tempo como cidadãos que clamam pela dignidade mas também participar do processo para atingí-la, bem como apontar caminhos para melhorá-la. 
Sabemos que nos últimos anos a enfermagem tem questionado $\mathrm{e}$ pesquisado sobre o seu papel, a sua inserção na sociedade, a sua forma de atuação e até mesmo sobre o posicionamento de que o cuidado é a essência da práxis da enfermagem.

Cianciarullo (1988), Boehs \& Patrício (1990), Waldow (1992) e Silva (1994) salientam sobre a necessidade da enfermagem concentrar-se no cuidado, definindo o seu campo de ação e os meios para efetivá-lo mas, ainda assim, apesar de mobilizaçôes como essas, o que se observa é o comodismo e a falta de comprometimento.

$\mathrm{Na}$ perspectiva de inovação, Silva (1994: 29) afirma que, na busca da eficiência e da eficácia, a enfermagem deve assumir

"sua responsabilidade, direcionando suas atividades técnico-assistenciais e administrativas na busca de estratégias de controle de suas ações, para garantia da qualidade da assistência prestada aos pacientes."

Já se fala hoje na inversão das bases da pirâmide administrativa onde o cliente passa a ser a parte principal numa organização ou serviço. Não podemos, entretanto, ser ingênuos a ponto de acreditar que a produtividade deixou de ter o seu valor e mérito, mas devemos enxergá-la através da ótica de que ela é consequeência e não meio.

Voltando para a enfermagem, apesar de algumas tentativas isoladas de conduzir o serviço de acordo com as abordagens mais modernas calcadas nos princípios da participação e da valorização humana, na maioria das instituições públicas ou privadas, o sistema de trabalho ainda é aquele do início do século, ditado por Taylor, Fayole Weber.

Entendemos, portanto, que se faz necessário buscar uma nova abordagem que venha associar-se às outras existentes e assim formar conceitos e ações que conduzam à satisfação das pessoas através do domínio da qualidade. Para tanto, a abordagem da Gestão pela Qualidade Total (GQT) parece suprir as necessidades acima, pois implica em valorização do ser humano e a busca da otimização dos processos para a obtenção de melhores resultados.

\section{GESTÃO PELA QUALIDADE TOTAL (GQT)}

O Controle da Qualidade Total (CQT), ou Gestão pela Qualidade Total (GQT) como está sendo chamado no Brasil, é um sistema administrativo que foi aperfeiçoado no Japão logo após a II Guerra Mundial, a partir de idéias americanas.

Segundo Campos (1992:41),

"O controle da qualidade total é um novo modelo gerencial centrado no controle do processo, tendo como meta a satisfação das necessidades das pessoas."

No Brasil, as atividades da GQT, iniciaram-se em 1971 e, hoje, o país já é considerado o segundo mais envolvido no movimento da qualidade pelo mundo. As suas ações têm se expandido também no setor de serviços, entretanto, no setor da saúde, as tentativas de implantação e avaliação da sua efetividade resumem-se ainda a tentativas isoladas com pouca divulgação.

No presente texto, os termos cliente, paciente e usuário são utilizados como sinônimos. 
Essa abordagem é fundamentada por teorias da administração como as proferidas por Taylor e Mayo; pelo emprego da estatística; no método cartesiano; e nos fatores de motivaçăo humana, segundo Maslow e Herzberg. As dimensões compreendidas na qualidade săo aquelas relacionadas à qualidade intrínseca, ao custo, à entrega, à moral e à segurança. A presente abordagem estabelece uma série de procedimentos e ferramentas que devem ser adaptados e monitorados de acordo com o contexto ou serviço para a otimizaçăo dos processos.

No gerenciamento da GQT, o gerente tem a responsabilidade de operacionalizar a política de qualidade determinada pela empresa e implica nas dimensões de desenvolvimento, implantação e controle, bem como a coordenaçăo das atividades para a obtençăo da qualidade. Neste sistema, cabe também ao gerente executar atividades que visem ao cumprimento dos padrões estabelecidos para os produtos, a adoçăo de medidas preventivas para as nåo conformidades e ainda replanejar / melhorar continuamente. Dessa forma, o controle dos processos é a atividade principal do gerente e, para tanto, é fundamental que ele domine as ferramentas e técnicas necessárias.

Para direcionar toda a prática gerencial de uma empresa alicerçada na GQT, é utilizado o ciclo PDCA (figura 1), que consiste num método formado de quatro fases dinåmicas e interativas aplicável às açőes de planejamento, manutençăo e melhoria da qualidade. No cerne da GQT, encontram-se os princípios de outras teorias administrativas formando um modelo eclético e inovador. Dessa forma, ele conjuga uma alternativa humana e racionalizadora que conduz as pessoas à maior reflexão e mudanças, comprometendo-se com a qualidade.

Em nosso país, essa abordagem tem surgido como um modelo de vanguarda e, segundo os seus seguidores, pode ser aplicado em qualquer organizaçăo.

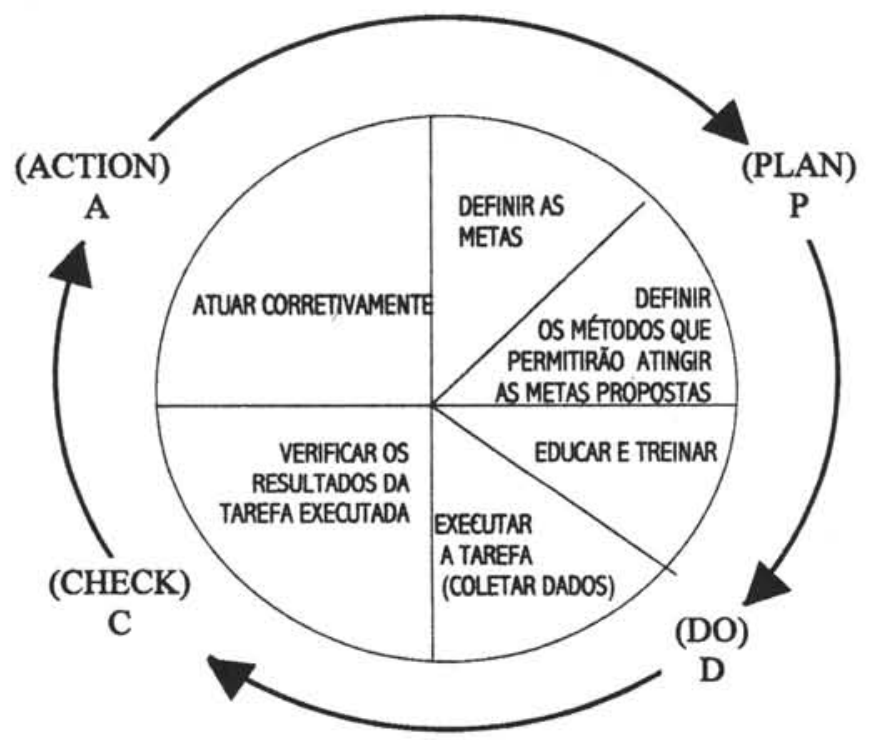

FIGURA 1 -CICLO PDCA DE CONTROLE DE PROCESSOS

FONTE: CAMPOS (1992:30). 
De acordo com o contexto da enfermagem a introdução de qualquer iniciativa que proponha uma metodologia de trabalho visando o inter-relacionamento e a interdependência entre planejadores e executores, alicerçados na participação e respeito mútuos, é vista como um desafio. Felizmente, em nosso meio, estes conceitos já começam a tomar corpo impulsionando os profissionais a refletirem melhor, conforme observamos nos relatos publicados pelo COREN-SP (1997).

Dentre as maiores dificuldades para a implantação da abordagem da GQT na enfermagem, estão aquelas mencionadas por Mendes (1993) que se relacionam às especificidades dos meios de produção e do produto, bem como a resistência na mudança de filosofia institucional citada por Mezomo (1994). Acreditamos que a GQT desponta como uma alternativa segura e viável para a efetivação da enfermagem. Entretanto, o seu conteúdo e prática carecem de profundas reflexões e adaptações.

Estando em conformidade com a perspectiva de gestão até aqui abordada, consideramos que o planejamento é função básica, que conduz à qualidade do serviço. Sobre essa ótica, a enfermagem parece dispor de um amplo espaço para a sua aplicação e desenvolvimento.

Ciampone (1991: 56), ao falar da

"utilização da metodologia do planejamento na enfermagem", enfatiza que este deve ser efetuado por toda equipe e que "somente assim, os planos seriam menos teóricos e mais adequados à realidade".

Neste âmbito, Cheng et al. (1995) também ressaltam sobre a necessidade da participação de equipes interfuncionais no planejamento.

Ainda Ciampone (1991: 57) alerta para que a função de planejamento não seja vista apenas no contexto

"do processo de enfermagem ou com a sistematização da assistência"

e reforça que é necessário perceber que o planejamento pode e deve ser aplicado a outras atividades. Acresce também que, para a sua elaboração, o enfermeiro deve visualizar o contexto interno e externo em que o serviço está inserido.

\section{O PLANEJAMENTO DO SERVIÇO DE ENFERMAGEM}

A Lei $n^{\circ} 7.498$, de 25/08/86, regulamenta o exercício da enfermagem no Brasil e, no art. 11, estabelece as atividades do enfermeiro. Dentre elas, estão as atividades administrativas de planejar, organizar, coordenar, executar e avaliar os serviços e a assistência de enfermagem.

Observamos, porém, que o planejamento, como uma das funções do enfermeiro e objeto do presente estudo, não tem ocorrido na prática da maioria destes profissionais.

Segundo Antunes (1993:38), a razão deste fato ocorrer está no

"desconhecimento da importância do processo de planejamento por parte dos enfermeiros."

No enfoque da qualidade, o planejamento compõe um capítulo próprio dentro da abordagem da Gestão da Qualidade Total (GQT), envolvendo todo o contexto em que vai ser efetuado. 
Não obstante haja diferenças entre os conceitos existentes nas indústrias de manufatura e na indústria da saúde, acreditamos que, nesta, embora haja alto grau de especificidade, efetuando-se algumas adaptaçōes, os mesmos princípios e métodos poderão ser utilizados.

Embasado nos conceitos e princípios do GQT, o método Desdobramento da Função Qualidade (QFD) surgiu como um modelo prático, sendo considerado uma ferramenta indispensável para viabilizar o planejamento da qualidade. O método consiste em levantar as necessidades dos clientes e, a partir daí, proceder-se a desdobramentos e priorizações sucessivas até chegar à padronização e monitoração contínua dos processos. Kaneko (1994:48) assevera que o QFD

"é uma das estratégias administrativas mais efetivas e valiosas" pois conduz a empresa "a compreender a utilidade do seu serviço...". Cheng (1995:24) afirma que o QFD é "uma forma de comunicar sistematicamente a informação relacionada a qualidade e de explicitar ordenadamente o trabalho relacionado à obtenção da qualidade."

Os princípios norteadores para a sua utilização estão relacionados à subdivisão e unificação, pluralização e visibilidade e à totalização e ao parcelamento dos processos. A seguir, apresentaremos as etapas e as ações propostas pelo QFD no planejamento do serviço de enfermagem bem como a metodologia utilizada. O Quadro 1 mostra também as quatro fases do ciclo PDCA na atividade de planejamento.

\section{QUADRO DEMONSTRATIVO 1 - ETAPAS DO PLANEJAMENTO DA QUALIDADE DO SERVIÇO DE ENFERMAGEM ESTABELECIDAS DE ACORDO COM O MÉTODOO QFD E A INSERÇĀO NO CICLO PDCA.}

\begin{tabular}{|l|c|}
\hline \multicolumn{1}{|c|}{ ETAPAS } & CICLO \\
\hline 1-Definir/delimitar os clientes & \\
2-Identificar as necessidades dos clientes & \\
3-Determinar as qualidades exigidas & \\
4-Priorizar as necessidades dos clientes & \\
5-Traduzir a "voz dos clientes" para a linguagem técnica de enfermagem & \\
/estabelecimento das características do serviço de enfermagem & \\
6-Estabelecer formas de avaliação das características de qualidade do serviço de & $\mathrm{P}$ \\
enfermagem & \\
7-Priorizar as características do serviço de enfermagem & \\
8-Estabelecer "valores-padrão" para as características & \\
9-Listar os procedimentos de enfermagem & \\
10-Priorizar os procedimentos de enfermagem & \\
11-Detalhar/redefinir os procedimentos de enfermagem para atender as & \\
características estabelecidas & \\
12-Documentar os procedimentos num "Manual Provisório" & \\
13-Propor meios para treinar as pessoas de acordo com o "Manual Provisório" & D \\
14-Executar o serviço de acordo com o "Manual Provisório" & \\
15-Propor meios para acompanhar e avaliar o cumprimento e os resultados dos & \\
procedimentos & \\
16-Revisar o "Manual Provisório" e estabelecer o "Manual Definitivo" para o serviço & \\
de enfermagem & \\
17-Refletir continuamente sobre os "procedimentos" executados no planejamento & $\mathrm{A}$ \\
do serviço de enfermagem. & \\
\hline
\end{tabular}


Conforme consta no Quadro, para maior detalhamento e clareza do método, foram estabelecidas 17 etapas. Vale lembrar que nas fases 6 e 8 , os meios e os valores sugeridos para o controle das Características de Qualidade foram determinados aleatoriamente, visto que não dispúnhamos de parâmetros anteriores que subsidiassem as nossas propostas.

No estudo, utilizamos como principal referencial teórico os enunciados de Cheng et al. (1995). Esses autores referenciam que o planejamento é constituído de oito etapas básicas que devem ser inseridas no ciclo PDCA a fim de se efetuar um melhor controle sobre o processo.

\section{METODOLOGIA}

Esta pesquisa foi desenvolvida por meio de um estudo exploratório-descritivo em que os dados foram coletados em duas fases em dois hospitais gerais filantrópicos de médio porte da cidade de Ribeirão Preto, Estado de São Paulo, durante os meses de julho e agosto de 1996. A primeira fase contou com a participação de 106 clientes e a segunda, 8 clientes.

Implicações éticas - primeiramente, obtivemos a autorização formal das instituições para a realização da pesquisa. Em seguida, certificamos através do prontuário médico, enfermeiro ou médico, quanto aos requisitos necessários ao cliente para compor a amostra.

Antecedendo a entrevista, todos os clientes eram informados sobre o objetivo e técnica de coleta dos dados bem como a necessidade de um consentimento formal em participar da pesquisa, o que se efetuou através da assinatura de um documento em duas vias; uma via foi entregue ao cliente e a outra permaneceu com a pesquisadora.

De posse dos consentimentos, os clientes foram entrevistados durante 0 plantão da manhã ou tarde, de acordo com o período estabelecido.

Etapa 1 - Definir e delimitar os clientes e a amostra - Homens e mulheres, com idade mínima de 18 anos, orientados no tempo e espaço, com capacidade de verbalização, pós-cirúrgicos, com tempo mínimo de 72 horas de internação e que aguardavam alta hospitalar para as próximas 24 horas.

Etapa 2 - Identificação das necessidades dos clientes - Consistiu na coleta e início da organização dos dados. Esta fase contou com a participação de 106 clientes que se mostraram desejosos em participar da pesquisa. No final da coleta, era permitido ao respondente ler ou ouvir as suas respostas.

Foi utilizado um formulário com duas perguntas abertas, cujas respostas (necessidades ou dados originais) formaram 20 categorias. As seis categorias com maior freqüência encontram-se no Quadro 2. Posteriormente, as mesmas foram desdobradas para obtenção das Qualidades Exigidas. 
QUADRO 2 - PRINCIPAIS CATEGORIAS DE NECESSIDADES REFERIDAS PELOS CLIENTES E RESPECTIVAS FREQÜÊNCIAS

\begin{tabular}{|c|l|c|}
\hline Graduação & \multicolumn{1}{|c|}{ Categoria } & Frequência \\
\hline $1^{\circ}$ & ser educado & 13 \\
$2^{\circ}$ & ter boa comunicação & 66 \\
$3^{\circ}$ & atender rápido & 25 \\
$4^{\circ}$ & gostar do que faz & 23 \\
$5^{\circ}$ & ter experiência prática & 21 \\
$6^{\circ}$ & ter conhecimento teórico & 19 \\
\hline
\end{tabular}

Etapa 3 - Determinação das Qualidades Exigidas (QE) - As necessidades ou dados originais referidos pelo cliente foram desdobrados em níveis de forma que representassem as verdadeiras exigências dos clientes de maneira resumida, sistemática e concreta. As QE situam-se na dimensão do "O QUE FAZER".

No desdobramento, o primeiro nível consiste nos dados originais referidos pelo cliente. No nível secundário, estão também as exigências percebidas pela enfermagem e no nível terciário, as QE já são expressadas de forma concreta e operacional como consta na Quadro 3. Cabe lembrar que o número de níveis não são predeterminados.

\section{QUADRO 3 - EXEMPLO DE DESDOBRAMENTO DOS DADOS ORIGINAIS EM QUALIDADES EXIGIDAS}

\begin{tabular}{|l|l|l|}
\hline - Nivel Primário & - Nivel secundário & - Nivel terciário \\
\hline - ser educado & $\begin{array}{l}\text { - cortesia no atendimento } \\
\text { - paciência às solicitações }\end{array}$ & $\begin{array}{l}\text { - responde imediatamente as perguntas } \\
\text { - orienta sobre a rotina hospitalar } \\
\text { - fala compreensiva }\end{array}$ \\
\hline
\end{tabular}

Etapa 4 - Priorização das Necessidades dos Clientes - Esta etapa consistiu na fase da coleta de dados onde, através da atribuição de notas por parte de 8 clientes ( anexo 2), buscamos saber quais das Qualidade Exigidas (QE) eram mais importantes. A seguir, extraímos as médias aritméticas para obtenção das seis primeiras, a saber: dá explicações fáceis de entender; mantem o setor em ordem; procura diminuir a dor; faz os cuidados de acordo com a teoria; interessa-se em saber como está sendo cuidado; e prática para fazer os cuidados. Estes dados nos mostraram que o cliente valoriza mais os aspectos interacionais que os técnicos.

Etapa 5 - Estabelecimento das Características de Qualidade (CQ) do Serviço de Enfermagem - Desdobrando as QE em níveis, foram extraídas 11 características. As características encontram-se na dimensão do "COMO FAZER" e devem ser expressadas em termos quali-quantitativos como está apresentado no Quadro 4. Esta fase consistiu em converter a voz do cliente em características técnicas do serviço para avaliar se as necessidades dos clientes estão sendo atendidas. 
QUADRO 4 - MODELO UTILIZADO PARA O ESTABELECIMENTO DAS CARACTERISTICAS DE QUALIDADE DO SERVIÇO DE ENFERMAGEM

\begin{tabular}{|c|l|}
\hline Qualidades Exigidas & \multicolumn{1}{c|}{ Caracteristicas de Qualidade } \\
\hline $\begin{array}{l}\text { - responde imediatamente } \\
\text { as perguntas }\end{array}$ & $\begin{array}{l}\text { - tempo de espera para ser atendido } \\
\text { - taxa de atendimento das solicitações dos clientes } \\
\text { - quantidade de intercorrências } \\
\text { - número de reclamações } \\
\text { - taxa de clientes satisfeitos }\end{array}$ \\
\hline
\end{tabular}

Etapa 6 - Estabelecimento de Formas de Avaliação das Características de Qualidade (CQ) - Nesta fase, foram determinados os critérios, tipo de informaçōes e os responsáveis pelo acompanhamento e controle das CQ. Como exemplo citamos: para a $C Q$ taxa de clientes satisfeitos, a avaliaçăo será efetuada através do percentual mensal de satisfação dos clientes, obtidos pelo enfermeiro assistencial, por ocasião da alta hospitalar.

Etapa 7 - Priorizaçåo das CQ dos Serviços de Enfermagem - Foi efetuada através de uma matriz onde, nas linhas, colocamos os itens de Qualidade Exigida e, nas colunas, as Características de Qualidade. A seguir, efetuamos as correlaçőes considerando individualmente cada item de uma tabela e assinalamos no interior de cada célula com um dos símbolos abaixo.

\section{QUADRO 5 - SÍMBOLOS E VALORES UTILIZADOS NOS PROCESSOS DE CORRE- LAÇÃO E CONVERSĀO}

\begin{tabular}{|c|c|c|}
\hline Correlação & Simbolo & valor \\
\hline Forte & $\bigcirc$ & 9 \\
\hline Média & $\bigcirc$ & 3 \\
\hline Fraca & 人 & 1 \\
\hline Inexistente & em branco & 0 \\
\hline
\end{tabular}

Fonte: CHENG L.C. et al. QFD Planejamento da Qualidade. (1995: 105).

Terminadas as correlações, procedemos a conversão dos dados multiplicando o valor do símbolo pelo valor das $Q E$ e registramos no interior de cada célula. A seguir, somamos todos os valores de cada coluna e embaixo, na matriz, registramos com o peso absoluto. Do somatório dos pesos absolutos foram obtidos pesos relativos percentuais para cada característica, determinando, assim, as características mais importantes.

As seis características priorizadas foram: $1^{a}$ ) taxa de clientes satisfeitos; $2^{\mathrm{a}}$ ) taxa de atendimento das solicitações; $3^{a}$ ) número de inquéritos por questőes éticas; $4^{a}$ ) quantidade de intercorrências; $5^{a}$ ) tempo de espera para ser atendido e $6^{\mathrm{a}}$ ) número de registros no prontuário sobre procedimentos efetuados.

Etapa 8 - Estabelecimento dos "Valores-Padrăo" para as Características de Qualidade do Serviço de Enfermagem - Foram estabelecidas metas para a melhoria/manutençáo das características. Como exemplo citamos: para a característica taxa de atendimento de solicitações do cliente, estabelecemos o valor-padrão de $90 \%$ de atendimento por plantão.

R. Bras. Enferm. Brasília, v. 51, n. 1, p. 93-104, jan./mar., 1998 
Etapa 9 - Listagem dos Procedimentos de Enfermagem - Consistiu na escolha dos principais procedimentos que poderão resultar naquelas características. Foram escolhidos 17 procedimentos considerados como sendo os mais elementares e também por serem executados pela maioria dos membros da equipe de enfermagem. Entretanto, sabemos que os critérios estabelecidos devem corresponder a realidade de cada clínica.

Etapa 10 - Priorização dos Procedimentos de Enfermagem - Mais uma vez utilizamos uma matriz mantendo-se as $C Q$ nas colunas e nas linhas, colocamos os procedimentos. Efetuamos as correlações conforme a matriz I e procedemos a conversão, multiplicando o peso relativo percentual de cada característica pelo valor do símbolo e anotamos no interior de cada célula.

Para obter o grau de importância dos procedimentos, somamos todos os valores de uma linha e assinalamos no final da tabela no lado direito. Os seis procedimentos priorizados foram: $1^{\text {9}}$ ) desenvolvimento de relação de ajuda; $2^{\circ}$ ) passagem de plantão; $3^{\circ}$ ) anotações de enfermagem; $4^{\circ}$ ) verificação de sinais Vitais; $5^{\circ}$ ) internação/admissão e $6^{\circ}$ ) aspiração de secreções da orofaringe e traquéia.

Etapa 11 - Detalhar/Redefinir os Procedimentos de Enfermagem - Os seis procedimentos acima foram redefinidos de acordo com a literatura, a experiência profissional de 5 enfermeiros assistenciais ou docentes, a realidade institucional e principalmente, relacionados ao atendimento das necessidades do usuário.

A atividade desta etapa deve conduzir a padronização dos procedimentos após terem sido transmitidos a todo o pessoal de nível operacional. É importante salientar que a ilustração, sempre que possível, deve ser usada a fim de facilitar a compreensão.

Etapa 12 - Documentar os Procedimentos num "Manual Provisório" Após a redefinição dos procedimentos, é necessário documentá-los para que sirvam de guia para o treinamento, implementação, avaliação e revisão, até se chegar ao "Manual Definitivo" e, com isso, à padronização.

Etapa 13 - Propor Meios para Treinar as Pessoas de Acordo com o "Manual Provisório" - Para a obtenção da qualidade, é imprescindível que se invista em educação e treinamento de todas as pessoas.

Como estratégias, sugerimos palestras utilizando-se recursos audiovisuais, grupos de discussão, oficinas de trabalho, aulas teórico-práticas em laboratório e finalmente, atuação no local de trabalho acompanhado pela chefia imediata que já deverá estar familiarizada com os novos procedimentos e métodos de avaliação.

O treinando será avaliado através de uma ficha única que será utilizada tanto pela equipe de treinamento como pela chefia imediata.

Etapa 14 - Executar Serviços Conforme o "Manual Provisório" - Nesta fase, os procedimentos deverão ser efetuados de acordo com os passos propostos a fim de detectar as anomalias e assim propiciar as ações corretivas.

Etapa 15 - Propor meios para Acompanhar e Avaliar o Cumprimento e os Resultados dos Procedimentos - Os dados desta etapa, segundo Juran (1994), deverão ser coletados sob as condições de trabalho. Sugerimos que a equipe interprofissional também participe desta fase. 
Neste estudo, foram elaborados dois formulários: um para o acompanhamento dos treinandos e outro para o cliente. Vale lembrar que a avaliação deverá ocorrer de acordo com os procedimentos e características de qualidade priorizados.

Etapa 16 - Revisar o "Manual Provisório" e Estabelecer o "Manual Definitivo" - O "Manual Provisório" deverá ser redefinido tão logo as falhas sejam diagnosticadas ou quando outras necessidades surgirem.

Efetuadas as alterações, devemos preparar o "Manual Definitivo", entretanto, esses procedimentos deverão ser monitorados continuamente, pois as necessidades dos clientes mudam com o tempo.

Lembramos também que esse "Manual" deve permanecer em local de fácil acesso e em quantidade suficiente. Em unidades informatizadas, o uso deste sistema possibilita um meio rápido e fácil para as consultas.

17 - Refletir Continuamente sobre os Procedimentos executados no Planejamento do Serviço - Para sistematizar o processo de garantia da qualidade, é necessário o comprometimento de todos e a busca contínua da melhoria. Para tanto, as pessoas deverão discutir e refletir, constantemente, sobre os processos e resultados através de reuniões intra e interprofissional e a busca ativa de informações junto aos clientes e ex-clientes.

\section{CONSIDERAÇÕES}

Observando a trajetória administrativa da enfermagem que ao longo dos anos alicerçou a sua prática nos modelos de cada época, observamos que, apesar disso, o que predomina em nosso meio é o modelo secular voltado para manutenção da hegemonia do poder e consiste em ditar e manter a rigidez e a delimitação sobre o quê, como e quem fazer.

Num meio permeado pelo descontentamento dos profissionais, dos usuários e também dos governantes onde cada um visualiza o serviço sobre diferentes óticas, procuramos inserir um modelo de trabalho buscando subsídios em uma nova abordagem de modo que se obtenha a humanização, a democratização e a otimização do serviço de enfermagem.

Sabemos que ao propor ganhos também estão implícitas as perdas mas, no caso da enfermagem, defendemos a idéia de que a perda, se houver, é necessária e pouco significativa. Hoje, a sociedade está mais exigente e consciente dos seus direitos buscando melhores serviços, com menor risco, a preços mais acessíveis.

De acordo com o contexto acima os profissionais que não compreenderem a perspectiva da Qualidade e com isso não mudarem a sua conduta e prática, certamente sucumbirão à modernidade e àqueles que buscam melhorar os seus serviços.

Em nosso entender, o método Desdobramento da Função Qualidade apontou um caminho inovador a ser buscado pela enfermagem pois as suas etapas são determinadas por objetivos e dados concretos. Não obstante, esse método necessita de aprofundamentos e adequações pois, a enfermagem possui especificidades que dificultam a previsão e a lógica. 


\section{REFERÊNCIAS BIBLIOGRÁFICAS}

1. ANGERAMI, E.L.S. \& CORREIA, F.A. Em que consiste a enfermagem. São Paulo, R. Esc. Enferm. USP, v. 23, n. 3, p.337-344, dez. 1989.

2. ANTUNES, A.V. O processo de planejamento na administração do serviço de enfermagem hospitalar. Ribeirão Preto: EEUSP, RP, Dissertação (Mestrado).

3. BEHS, A.E \& PATRÍCIO, Z.M. O que é este cuidar cuidado? - uma abordagem inicial. R. ESC. Enferm. USP, São Paulo, v. 24, n. 1, p. 11-116, abr. 1990.

4. CAMPOS, F.F. Controle da qualidade total (no estilo japonês). 2. Ed. Rio de Janeiro: Bloch, 1992.

5. CHENG, L.C. ET AL. QFD: Planejamento da qualidade. Belo Horizonte: Líttera Maciel, 1995. Cap. 1 e 2, p. 3-54.

6. CIAMPONE, M.H.T. Metodologia do planejamento na enfermagem. In: KURGANT et al. Administração em enfermagem. São Paulo: EPU, 1991. Cap. 4, p.41-58.

7. CIANCIARULLO, T.I. Análise retrospectiva da qualidade de assistência de enfermagem em um hospital universitário. São Paulo: EEUSP 1988. Tese (Livre Docência).

8. COREN-SP. Globalização força o surgimento de novas tendências na enfermagem.. Ano 20, n. 11, jul/ago., 1997. p. 6-7.

9. JURAN, J.M. Juran planejando para a qualidade. Trad. de João Mário Csillag e Cláudio Csillag. 2 ed. São Paulo: Pioneira, 1992.

10. KANEKO, N. QFD (quality function deployment). Trad. de Manuel Matías Ojeda et al. Centro de Calidad, Monterrey, México, 1994.

11. MENDES, V.L.P. Gerenciando qualidade em serviços de saúde. R. Bras. de Enferm., Brasília, v. 46, n. 3-4, jul./dez., 1993.

12. MEZOMO, J.C. Visando a qualidade hospitalar. Hospital - Adm. e Saúde. v. 18, n. 3, mai./jun., 1994.

13. SILVA, S.H. da. Controle da qualidade da assistência de enfermagem implementação de um modelo. São Paulo, 1994. EEUSP. Tese (Doutorado).

14. WALDOW, V.R. Cuidado uma revisão teórica. R. Gaúcha de Enferm. Porto Alegre. v. 13, n. 2, p. 29-35, jul. 1992. 